\title{
Clinical Outcome of Hereditary Breast Cancer in the Lithuanian Population
}

\author{
Pavel Elsakov', Juozas Kurtinaitis', Valerii Ostapenko' \\ IVilnius University Institute of Oncology, Santariskiu 1, 2021 Vilnius, Lithuania; 2Lithuanian Cancer Registry, Polocko 2, 2007, Vilnius, Lithuania
}

Key words: hereditary breast cancer, early hereditary cancer, relative risk (RR)

Corresponding author: Dr. Pavel Elsakov, Vilnius University Institute of Oncology, Santariskiu 1, 2021 Vilnius, Lithuania

Submitted: 10 March 2005

Accepted: 20 April 2005

\begin{abstract}
Breast cancer family history has been known to be one of the main cancer risk factors. Members of high-risk families should be given recommendations which may improve prophylaxis, early diagnosis and treatment. Detection of high-risk families is possible by identification of mutations in cancer susceptibility genes like BRCA1 and BRCA2 as well as by family history showing breast and/or ovary cancer aggregation. In a group of 521 breast cancer patients we identified 26 patients with hereditary breast cancer who fulfilled the following criteria: one more relative with breast cancer, vertical transmission, at least one breast cancer patient affected at the age under 50 years. 8 patients of these developed second primary breast cancer. We also compared the frequency of hereditary cancers in stage I-III with the frequency of respective cancers with negative family history. Hereditary breast cancers were diagnosed less frequently in stage I and more frequently in stage II and III $(R R=0.49, R R=1.39, R R=1.62$, respectively). Because of importance of family history as well as genetic testing for breast cancer susceptibility genes (BRCA1/2), it is necessary to create a nationwide network of hereditary cancer clinics for proper diagnosis, treatment, and prophylaxis of these patients.
\end{abstract}

\section{Introduction}

Cancer family history has been known to be one of the main risk factors. Members of high-risk families should be given recommendations which may improve prophylaxis, early diagnosis and treatment [1-4]. During the last 10 years, the knowledge of cancer genetics has increased substantially. Now it is possible to identify several genes involved in the hereditary forms of some types of cancers including breast cancer [5-6]. Hereditary forms of breast cancer are mostly caused by mutations in such genes as BRCA1 and BRCA2 and are thought to account for $5-10 \%$ of all cases of breast cancer [3]. Because of high penetration of mutated genes as well as autosomal dominant trait, female family members are frequently affected with breast cancer, therefore taking the family history is a major, effective and cheap way of diagnosing hereditary forms of breast cancer. Clinical outcome of hereditary breast cancer differs from sporadic cases. Primary tumour growth is different than sporadic ones, and it seems that early detection of hereditary forms may be more difficult. Affected patients with the hereditary form of breast cancer are also at increased risk of the development of the second primary breast cancer. The purpose of this work was to evaluate in Lithuanian breast cancer patients such clinical factors as: frequency of diagnosis of primary breast cancer in clinical stage I-IV and frequency of the second primary breast cancer in groups with a hereditary form. In order to identify patients suspected for hereditary breast cancer specific pedigree criteria were applied. 
Table 1. Breast cancer in a study group and in a population by cancer stage

\begin{tabular}{lcccc}
\hline Stage (TNM) & Number of cases in a study group & Number of cases in a population* & Relative risk (RR) \\
\hline I & 3 & 24 & 0.49 \\
\hline II & 16 & 45 & 1.39 \\
\hline III & 7 & 17 & 1.62 \\
\hline IV & 0 & 14 & - \\
\hline Unknown & 0 & 2 & - \\
\hline Total & 26 & 102 & - \\
\hline
\end{tabular}

*) matched by age and territory with the study group, 2000

\section{Materials and methods}

In 2001 in Vilnius University Institute of Oncology there were 521 patients treated for breast cancer. Patients suspected for site specific hereditary breast cancer were identified according to the following pedigree criteria: mother and daughter affected by breast cancer; one of them developed breast cancer under the age of 50 years. Every case of hereditary breast cancer was analysed retrospectively by stage according to TNM classification and compared with the control group which was selected from sporadic cases diagnosed in the same cancer centre and matched for the same age of diagnosis. The frequency of each stage rates was calculated for study and control groups. The relative risk was used as an estimate of the relative effectiveness for the recruitment cases by stage. Relative risk was calculated by stage as a ratio at each category to the total number of observation. The frequency of the development of the second primary tumour in the hereditary breast cancer group was calculated.

\section{Results and discussion}

In a group of 521 patients treated with breast cancer in Vilnius University Institute of Oncology in 2001 , there were 26 patients from 25 families with family history indicating diagnosis of site specific hereditary breast cancer. All these patients were affected with primary breast cancer under the age of 50 years, which is in concordance with the early age of onset observed in patients with positive breast cancer family history. We evaluated the frequency of breast cancers diagnosed in clinical stages I-IV in hereditary cancer patients. To avoid possible differences in diagnostic effectiveness between diagnostic centres in Lithuania, a control group was selected from sporadic breast cancer cases diagnosed in the same cancer centre and matched for the same age of diagnosis. Comparison of breast cancer frequencies diagnosed in clinical stages I-IV is shown in Table 1. We observed much lower frequency of hereditary cases diagnosed in stage I than sporadic ones (11\% vs. $23 \%, R R=0.49$ ). In contrast hereditary breast cancer cases were diagnosed more often than sporadic tumours, in advanced stages (stage II in $61 \%$ vs. $44 \%, R R=1.39$; and stage III in $27 \%$ vs. $17 \%, R R=1.62$, respectively). We have not observed any hereditary breast cancer patient diagnosed in clinical stage IV, which can be caused by the low number of studied cases. The low rate of hereditary cancers diagnosed in stage I and high rate of stage II and III may suggest that growth of these tumours may be accelerated and standard surveillance is less effective than in a group of patients without family history. Similarly to other observations, cancer family history is correlated with an increased risk of contralateral breast cancer. In our group of 26 patients, 8 demonstrated bilateral breast cancer. Experience of many foreign hereditary cancer centres proved that hereditary cancer patients as well as their family members must be followed in an institution prepared for biological genetic testing and specialist surveillance. A better understanding of the process of coupling in healthy people with a genetic risk of cancer including genetic consultations is relevant here to make a decision about prevention or screening [7-11].

The results of this study show the need to create a Lithuanian specialist centre for hereditary cancer diagnosis, treatment, and prophylaxis, which will coordinate and connect work between different specialists.

\section{Acknowledgements}

This study was supported by a grant of EC project QLRI-CT-1999-00063 "Development of network of cancer family syndrome registries in Eastern Europe". We thank Dr Jacek Gronwald for his suggestions. 


\section{References}

1. Burke W, Petersen G, Lynch P, Botkin J, Daly M, Garber J, Kahn MJ, McTiernan A, Offit K, Thomson E and Varricchio C. Recommendations for follow-up care of individuals with an inherited predisposition to cancer. I. Hereditary nonpolyposis colon cancer. Cancer Genetics Studies Consortium. JAMA 1997; 277: 915-919.

2. Burke W, Daly M, Garber J, Botkin J, Kahn MJ, Lynch P, McTiernan A, Offit K, Perlman J, Petersen G, Thomson E and Varricchio C. Recommendation for follow-up care of individuals with an inherited predisposition to cancer. II. BRCA1 and BRCA 2. Cancer Genetics Studies Consortium. JAMA 1997; 277: 997-1003.

3. Eisinger F, Alby N, Bremond A, Dauplat J, Espie M, Janiaud P, Kuttenn F, Lebrun JP, Lefranc JP, Pierret J, Sobol H, Stoppa-Lyonnet $\mathrm{D}$, Thouvenin D, Tristant $\mathrm{H}$ and Feingold J. Recommendations for medical management of hereditary breast ovarian cancer: The French National Ad Hoc Committee. Ann Oncol 1998; 9: 939-950.

4. Eisinger F, Nogues C, Guinebretiere JM, Peyrat JP, Bardou VJ, Noguchi T, Vennin P, Sauvan R, Lidereau R, Birnbaum D, Jacquemier J and Sobol H. Novel indications for BRCAl screening using individual clinical and morphological features. Int J Cancer 1999; 84: 263-267.

5. Frank TS and Critchfield GC. Hereditary risk of women's cancers. Best Pract Res Clin Obstet Gynaecol 2002; 16 (5): 703-713.

6. Liede A and Narod SA. Hereditary breast and ovarian cancer in Asia: genetic epidemiology of BRCA1 and BRCA2. Hum Mutat 2002; 20 (6): 413-424.

7. Hoskins IA. Genetic counseling for cancer patients and their families. Oncology 1989; 3: 84-92.

8. Houlston RS, Murday V, Harocopos C, Williams CB and Slack J. Screening and genetic counselling for relatives of patients with colorectal cancer in family cancer clinic. BMJ 1990; 301 : 366-368.

9. Murday V. Genetic counselling in the cancer family clinic. Eur J Cancer 1994; 3A: 2012-2015.

10. Julian-Reynier C, Eisinger F, Chabal F, et al. Cancer genetic consultation and anxiety in healthy consultees. Psychol Health 1999; 14: 379-390.

11. Gershoni-Baruch R, Dagan E, Fried G, Kepten I and Robinson E. BRCA1 and BRCA2 founder mutations in patients with bilateral breast cancer. Eur J Hum Genet 1999; 7: 833-836. 